\title{
The role of self-control and regulatory foci in money-saving behaviours among children
}

\author{
Agata Trzcińska $^{1,2}$ (D) Katarzyna Sekścińska ${ }^{2} \cdot$ Dominika Maison $^{1}$
}

Published online: 3 August 2018

(C) The Author(s) 2018

\begin{abstract}
The studies aimed to discover if it is possible to increase children's ability to defer consumption in favour of saving money by drawing attention to the importance of self-control and by inducing regulatory focus of promotion or prevention. The first study confirmed that economic behaviours of children are connected to their level of self-control. Next, in two experimental studies, self-control and regulatory focus were experimentally induced in 9- to 11-year-old children. The second study $(n=158)$ showed that self-control activation results in preference of saving over immediate consumption for boys but not for girls. The third study $(n=144)$ showed that promotion regulatory focus activation results in preference of saving over immediate consumption, while after the activation of prevention regulatory focus, children prefer immediate consumption. The results indicate that sole activation in children's thinking about the importance of self-control or about specific self-regulation motivations may influence saving behaviours. Nevertheless, due to the fact that males and females differ in self-control levels and in motivation for goal pursuit, inducing self-control or specific regulatory focus in children may have different effects on economic decisions, depending on a child's gender.
\end{abstract}

Keywords Saving money $\cdot$ Self-control $\cdot$ Regulatory focus $\cdot$ Children $\cdot$ Economic behaviour

\section{Introduction}

Various researchers have already presented the life-long benefits of teaching children good money habits (see Ashby et al. 2011; Lyons 2003). It is worth emphasising that 6- to 7-year-old children already often have their own money and learn to make their own decisions about spending and saving money (Kupisiewicz 2004). Moreover, at this age, children begin to develop money habits that will be the basis for the attitudes and behaviours in adulthood (Ashby et al. 2011; Goszczyńska 2010). Researchers who study economic socialisation (e.g., Berti and Bombi 1988; Rudzińska-Wojciechowska et al. 2011) showed that children around 9 to 11 years of age know the meaning of saving and begin to manage their pocket money.

Agata Trzcińska

atrzcinska@psych.uw.edu.pl

Institute for Social Studies, University of Warsaw, Warsaw, Poland

2 Faculty of Psychology, University of Warsaw, ul. Stawki 5/7, 00-183 Warsaw, Poland
Therefore, the group of 9- to 11-year-old children seems to be very interesting in terms of good or bad financial habit learning.

The scope of activities included in the concept of economic socialisation is usually connected with the statement that children may acquire economic behaviours and habits from the observation of others or from their own experiences. It was shown that providing a child pocket money and parental encouragement to save may influence a child's economic decisions (e.g., Webley and Nyhus 2006, 2013). However, individual traits or states may also influence people's financial behaviours. Previous studies showed that one of the most important internal factors that may influence children's financial behaviours were self-control skills (Otto 2009; Trzcińska and Goszczyńska 2015). The present studies aimed to expand the aforementioned studies by answering the question of whether it is possible to increase the desirable economic behaviour (e.g., the ability to defer consumption in favour of saving) through the reinforcement of self-control (de Ridder et al. 2012) or by inducing in the child specific self-regulatory foci (Higgins 1987, 1997, 1998) that are responsible for different self-control strategies people use when they attain their goals. In our studies, those internal factors (self-control and 
self-regulation) were experimentally induced, and due to that causal relation between those factors and saving, behaviour could be determined.

\section{Self-Control in Children's Economic Decisions}

Self-control is an ability to alter dominant response tendencies and to regulate behaviour, thoughts and emotions (de Ridder et al. 2012). People with more self-control are more likely to attain their goals and be more successful in various life domains (de Ridder et al. 2012). At the same time, children who present better self-control achieve greater success in adult life. The seminal work of Mischel and colleagues (Mischel et al. 1988; see also Ayduk et al. 2000; Shoda et al. 1990) showed that a child's self-control ability (delaying gratification) predicted success in the academic, social, cognitive, and emotional domains during adolescence and adulthood.

One of the life domains that can be highly influenced by self-control is effectiveness in saving money, which might be a consequence of the ability to delay gratification. Thaler and Shefrin (1981), in their Behavioural Life Cycle Theory, assumed self-control as one of the main factors that influences the behaviour of saving. Subsequent empirical studies (Brändstatter and Güth 2000; Otto 2009; Trzcińska and Goszczyńska 2015) confirmed this hypothesis by showing that a high level of self-control is conducive to saving money, both among adults as well as among adolescents.

It should be emphasised that self-control is the ability that naturally develops during the life span. As individuals mature, they shift from stimulus-response behavioural orientation to a rule-based cognitive orientation (Kendler et al. 1969). Several studies (e.g., Hay and Forrest 2006; Higgins et al. 2009; Vazsonyi and Jiskrova 2017) found that self-control ability significantly increases during childhood, but its level stabilises sometime between the ages of 8 and 10 years. Then, up to the age of 15 , the majority of children show considerable stability in self-control (Hay and Forrest 2006). However, despite the relative stability of self-control level, by the age of 9 to 10 years, self-regulatory mechanisms are still poorly developed (Pechman et al. 2005). It means that children and adolescents may struggle with higher temptations than adults while saving, because they have weaker self-regulatory skills than adults. From this point of view, self-control appears to be particularly important for economic choices of children.

Since self-control is still poorly developed in 9- to 11-yearold children and, at the same time, can be important for children's and young people's saving behaviours, one could raise the question of whether increasing self-control ability in children can affect their economic choices. Mischel (2014) insists that self-control skills can be developed and strengthened over time. Previous studies described below showed that selfcontrol is an individual trait that can be modified under some conditions and with various methods: self-control trainings or cognitive activation of self-control concept. Self-control trainings are based on the strength model, which compares selfcontrol to a physical muscle (Muraven and Baumeister 2000). This model suggests that exerting self-control leads to temporary reductions in self-control performance (ego depletion) (Baumeister et al. 1998), but practising self-control repeatedly over time may lead to the improvement of self-control ability (Muraven et al. 1999). Some studies reported this effect (see Hagger et al. 2010), but recent results (Miles et al. 2016) revealed several methodological problems with those findings and observed that self-control trainings did not always improve self-control. Besides self-control trainings, researchers tried to improve self-control through cognitive activation of self-control concepts in people's minds. Lindroos (2015) showed that simple verbal sentences could be exogenous facilitators of self-control in hypothetical financial delay discounting. Taking into account those findings, we decided to use in our studies the method of cognitive activation of selfcontrol concepts in children's minds. We were interested if mental and non-specific (not related to financial behaviour) activation of the self-control concept is enough to influence not only hypothetical financial decisions (as in studies of Lindroos 2015) but also economic behaviours. Since, as mentioned above, self-control is responsible for saving activity, in our research, we hypothesised that it should be possible to increase in children the desirable economic behaviour (the ability to defer consumption in favour of saving) through activating thinking about the importance of self-control.

\section{Regulatory Focus in Economic Decisions}

Self-control mainly refers to goal-achieving effects but neglects the process of goal pursuit, e.g., ways people approach a task or a goal. Different factors can motivate people during goal pursuit. Higgins, in his self-regulation theory, distinguished two separate systems of motivation: promotion and prevention (Higgins 1987, 1997, 1998). Promotion-oriented people are concentrated on achievements and aspirations. Moreover, they are inclined towards challenges and growth (Higgins 1997, 1998; Higgins et al. 2001). However, prevention-oriented people concentrate on fulfilling safety needs and achieving security. They are concerned about commitments, duties, and avoiding negative outcomes (Higgins 1997, 1998; Higgins et al. 2001).

The aforementioned characteristics of motivational systems led researchers to the conclusion that promotion- and prevention-oriented people may present different economic behaviours. Indeed, various studies pointed out that, in adults, the self-regulatory orientation (promotion or prevention) is related to individual economic behaviour (e.g., Förster and Werth 2007; Zawadzka et al. 2012). One of the economic domains that can be influenced by self-regulatory foci is 
saving behaviour (e.g., Sekścińska et al. 2016). It is worth noting that both promotion and prevention foci may facilitate saving behaviour but may have different consequences for the ways of delaying consumption. Recent research (Sekścińska et al. 2016) showed that a higher level of promotion motivation was associated with the preference to delay consumption. The same preference presented people with higher prevention motivation. It means that promotion and prevention foci are motivation pointing towards goals, and the strength of regulatory focus has a positive effect on self-control, which is crucial for saving activity. However, people with different regulatory foci (promotion vs. prevention) prefer different ways of delaying consumption. Sekścińska et al. (2016) showed that induced promotion motivation led to a higher propensity to invest money (allocating money to financial instruments that generate profits, i.e., stocks) but a lower inclination to save money (keeping the money in a nonprofitable form, i.e., non-interest-bearing bank account). It means that promotion focus is connected to meeting the growth needs and realisation of promotion goals (investing), while prevention focus is connected with the satisfaction of the safety needs and realisation of prevention goals (secure saving). Those results are in line with the research of Cho et al. (2014), who showed that promotion-oriented people were less prone to save for prevention goals, while, for preventionoriented people, the effect was opposite. This result leads to the conclusion that saving goal pursuit may depend not only on the strength of regulatory focus but also on regulatory fit. According to Higgins (2000), regulatory fit is a goal pursuit congruent with an individual's regulatory orientation. Researchers indicated that regulatory fit enhances persuasion (Lee and Higgins 2009) and improves performance (Shah et al. 1998) in various contexts.

Since regulatory focus seems to be important for decisions connected to refraining from consumption (saving and investing) in adults, one could raise a question of whether activating specific regulatory focus (promotion or prevention) could also influence children's economic decisions. Researchers indicated that the chronic regulatory focus is developed from an early age through socialisation processes (Higgins et al. 2001; Keller 2008; Lockwood et al. 2002), such as experiencing success in life history or parenting styles. However, the situational regulatory focus may be influenced by the characteristics of the task (Liberman et al. 2001; Shah et al. 1998; Zhou and Pham 2004), and it can be induced by different priming tools, for example, by (1) different task frameworks: with gain or no gain (activation of promotion focus) and loss or non-loss (activation of prevention focus) information (Förster et al. 2003), or (2) by activating knowledge structures that are related to nurturance needs (promotion focus) or security needs (prevention focus) (e.g., Friedman and Förster 2001). Taking into account that regulatory focus may be activated situationally in adults and may influence their economic decisions (e.g., Sekścińska et al. 2016), in our research, we hypothesised that such activation may also influence economic behaviours of children. Although relatively long ago researchers (Mischel et al. 1992) stated that children use different strategies in goal pursuit, there is a lack of studies on motivation in goal pursuit (i.e., regulatory focus) in children.

\section{Gender Differences in Self-Control and Regulatory Focus}

Gottfredson and Hirschi (1990), in their General Theory of Crime, assumed that females have higher levels of selfcontrol. According to those researchers, this occurs because parents use different educational practices for males and females (e.g., different levels of monitoring a child's behaviour, different evaluations of a child's behaviours). One of the first attempts to verify the assumption that females have a higher level of self-control than males was made by Higgins and Tewksbury (2006), who actually supported in their empirical research Gottfredson and Hirschi's (1990) contention. This result was confirmed in very recent research (Shoenberger and Rocheleau 2017), which showed that females have higher levels of selfcontrol than males and that this difference is accounted for by parenting factors. The difference in self-regulation was also assessed in five-year-old Norwegian children (Størksen et al. 2015). The results of this study indicated that girls outperformed boys in different types of behavioural regulation. Given that boys and girls may differ with respect to self-control levels, we hypothesise that activating the importance of self-control may impact girls and boys differently. Therefore, we expected different economic behaviour (saving) as a consequence of selfcontrol activation, depending on a child's gender.

Previous studies showed that males differ from females, not only in self-control levels, which is crucial for goal pursuit, but also in motivations for goal pursuit. McKay-Nesbitt et al. (2013) stated and confirmed the hypothesis that males tend to be more promotion than prevention focused when compared to females. This means that females are generally more motivated to realise safety goals, while males are more concentrated on satisfaction of growth needs and are more prone to be risk takers (Bryant and Dunford 2008). Taking into account that males and females differ with respect to chronic regulatory focus, it is probable that situational activation of prevention or promotion focus may have different impacts on children, depending on their genders. As a consequence, it will have a different impact on boys' and girls' economic behaviour (saving). 


\section{Present Studies}

The research presented in this paper aimed to answer two questions:

1. Can drawing the child's attention to the importance of self-control modify the child's economic behaviour?

2. Can inducing specific regulatory focus (promotion vs. prevention) modify the child's economic behaviour?

The studies outlined above show that children's moneysaving decisions might depend largely on a child's level of self-control and the regulatory foci. Moreover, previous research suggests that both self-control level and regulatory focus can be influenced (by activating thinking about the importance of self-control and by focusing the individual on promotion or prevention self-regulatory motivation). Taking those results into account, we hypothesised that raising the selfcontrol level or inducing specific self-regulatory focus may affect the economic decisions (concerning saving) of children. Although the practical utility and theoretical implications of such research would be extremely important, there is still a lack of studies that analyse the possibilities of influencing children's saving behaviours.

Taking into account aforementioned gender differences in self-control and regulatory foci, in our experiments we analysed the differences in experimental manipulation effects between boys and girls.

\section{Study 1 - Pretest}

Before answering the outlined research questions above, we conducted a pretest study with the goal to verify the hypothesis that economic behaviours of children are connected to their levels of self-control. The need for such analysis was due to the fact that earlier research indicating the relationship between self-control and economic decisions was conducted only on adolescents (Otto 2009; Trzcińska and Goszczyńska 2015) but not on 9- to 11-year-old children. Moreover, those studies analysed hypothetical economic decisions, while in our research, we wanted to investigate real economic behaviours of children.

\section{Participants}

In the first study, 62 Polish children (40 girls and 22 boys) aged 9 to 11 years $(M=10.17, S D=.69)$ took part. The research was carried out in four public primary schools in Warsaw, Poland. Parents of all the children provided written informed consent for their children's participation in the study. Children were also asked for their oral assent to take part in the study (all children assented).

\section{Measures}

At the beginning of the study, all children received five tokens from the experimenter and were presented with two options: (a) to exchange the obtained tokens for real products in the "shop" (immediate consumption) or (b) to deposit tokens in the "bank" for one week (saving). The "shop" and "bank" were set up for the purpose of the study. All children were informed that those who deposit tokens in the "bank" after one week would obtain six tokens instead of five, ${ }^{1}$ and then they would be able to use them at the same "shop" with the same assortment. Every child could choose only one option: "shop" or "bank"; it was not possible to use some tokens in the "shop" as well as deposit some in the "bank". In the "shop", children could choose different products but could spend a maximum of five tokens (if they decided to spend their tokens on the day of the study). A variety of products (notebooks, pens, stickers, rubber balls, playing cards, jewelry accessories, football cards, lollipops, chocolates, candy bars, candies, apples, juices) were offered in the "shop" to ensure that all children would find something interesting. Each product had a prescribed price of tokens. All children who deposited their tokens in the "bank" after one week were given the opportunity to spend their six tokens (five tokens plus one token of interest) for the same goods.

Self-control was measured by a self-reported questionnaire, which children filled out seven days after the "bank" vs. "shop" choice. The measure consisted of five questions selected from the 33-item Child Self-Control Rating Scale (CSCRS) (Rorhbeck et al. 1991). The items concerned the ability of the child to calm down when excited, wait for his/her turn to talk, not get distracted form work, think before answering the question and obey rules. The selection of items was based on high adjusted item-scale correlations in the original version of CSCRS, but we also paid attention to include different aspects of self-control covered by CSCRS. The selected items were translated into Polish using the technique of translation and back-translation, and experts reviewed them for cultural equivalence. For each question (e.g., "Some kids find it easy to calm down when excited, BUT other kids find it hard to calm down when excited"), the child was first asked to decide which kind of child is most like him or her and then asked whether this is only 'sort of true' or 'really true' for him or her. Items were scored on a four-point scale (e.g., for the answer 'finding it easy to calm down' and the additional statement that this is really true, four points were assigned). The total score (summed item scores) reflected the level of self-control. A

\footnotetext{
${ }^{1}$ The interest rate in our studies was quite high (20\%), because, according to previous studies, children in general show greater delay discounting than adults (Green et al. 1994; Steinberg et al. 2009). This means that, when children are asked to choose between an immediate reward of less value and a delayed reward of more value, they exhibit bias towards immediate gratification and expect a much higher interest rate than adults. Nevertheless, it would be interesting to conduct future studies with other interest rates.
} 
high level of self-control was indicated by a high value on this scale. The Cronbach's alpha for the original 33-item version of the scale was .90 (Rorhbeck et al. 1991), but for the shorter version used in our analysis, it was .66 $(N=172)$, probably due to the small length of the scale. Nevertheless, item-total score correlations were satisfying (above .40 ) and similar to the original version.

\section{Results}

Our hypothesis assumed that children who choose "bank" present a higher level of self-control than children who choose "shop". The results of our study confirmed the difference in the self-reported level of self-control between children who chose "bank" and those who chose "shop" $(\mathrm{t}(56)=2.058$, $p=.04)$. The mean level of self-control in children who chose "bank" was $14.67(\mathrm{SD}=3.44)$, while it was $12.60(\mathrm{SD}=3.11)$ in children who chose "shop".

\section{Study 2}

The results of the first (pretest) study indicate that the selfreported level of self-control is related to the economic behaviours of children. Hence, in the second study, we wanted to answer the question of whether the child's economic behaviour could be modified by drawing the child's attention to the importance of self-control. The main goal of this study was to examine the influence of induced thinking about the importance of self-control on a child's preference to save over immediate consumption. Given the results of the aforementioned studies, the following hypothesis was formulated:

\section{Hypothesis 1}

Induced thinking about the importance of self-control leads to preferring saving over immediate consumption.

\section{Participants}

In the study, 158 Polish children ( 73 girls and 85 boys) aged 9-11 years $(\mathrm{M}=10.41, \mathrm{SD}=.67)$ took part. The research was carried out in four public primary schools in Warsaw, Poland. Parents of all the children provided written informed consent for their children's participation in the study, and all children provided oral assent to take part in the study.

\section{Experimental Procedure and Materials}

The study was conducted individually with each child, randomly assigned to either the experimental condition $(n=76)$ or the control condition $(n=82)$. The study consisted of two parts run by different experimenters: (1) experimental manipulation with the manipulation effectiveness check; (2) measure of financial behaviour (saving or immediate consumption choice - DV).

The experimental manipulation took about one minute. An experimenter showed the child a short animated movie about: (a) the importance of self-control (experimental condition) or (b) the benefits of cycling (control condition). The movie at first clarified what self-control (experimental condition) or cycling (control condition) is and, after that, provided an explanation of how it might be helpful in everyday life (illustrated by examples from real life). The animation presented subtitles of the text, which the lecturer read, and some simple illustrations of children of similar age to those who took part in the study. One of the screens from the animation is presented in Fig. 1.

The film used in the experimental condition clarified that self-control is the ability to think before acting, controlling emotions, not giving up, preserving made decisions, refraining from doing something stupid, making wise choices, and not succumbing to temptations. The real-life examples, presented in the film, were, among others: "when you want to restrain from talking during the lesson", "when you first do your homework and you play later" and "when you are waiting for a bigger prize, resigning from something smaller now".2

The movie used in the control (neutral) condition explained benefits of cycling by saying that this ability helps with staying fit, moving to various places, having a good time, avoiding traffic jams, protecting the environment, and getting to know the surroundings better. The real-life illustrations in this condition were, for example: "when buses and cars are stuck in a traffic jam, but by bike you can quickly get to your friend", "when you go with your friends on a bike tour in the forest", and "when you are fed up with sitting on the couch and you want to do some outdoor activity".

Each child individually watched one of those films (about self-control or cycling) on the laptop monitor. The experimenter then asked the participant to answer two questions: "What was the film about?" and "What have you learned from the film?" (manipulation check). After the experimental manipulation, the child was given five tokens that were described as the reward for the participation in the experiment and could be exchanged for different products. In fact, those tokens were used in the second part of the study to measure the child's financial behaviour.

In the second part of the study, the second experimenter gave the child two options: (a) to exchange the obtained tokens for real products in the "shop" (immediate consumption) or (b) to deposit the tokens in the "bank" for one week

\footnotetext{
$\overline{2}$ The self-control involves (among others) resigning from immediate small rewards in favour of future larger rewards. In our movie, we wanted to capture all aspects of self-control, but we did not want to connect them to the second part of the experiment (saving money). To avoid the situation in which the movie explicitly tells the children what to do in the second part of the experiment (save money), we illustrated this sentence with pictures of gifts (small and big).
} 


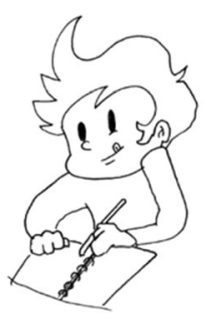

Riedy majpierw odpabiasz prace

\section{domowag @opiero}

\section{pofem zajmgjesz sier zabar}

Fig. 1 Screen from the animated movie used for the experimental condition in Study 2 (translation: "when you first do your homework and you play later")

(saving) and gain one more token. This part of the experiment measured the child's economic behaviour, i.e., the choice made by the child ("bank" or "shop"), and was exactly the same as the first study.

\section{Results}

Our hypothesis assumed that children from the experimental condition (induced thinking about the importance of self-control) would choose "bank" more often than children from the control group who watched the neutral film (about cycling). The results of our experiment revealed that choosing "bank" (saving option) occurred more often in children from the experimental group who watched the film about the importance of self-control $(77.32 \%)$ than in a control group $(56.10 \%), \chi^{2}(1)=$ $7.167 ; p=.007$. These data support Hypothesis 1 in arguing that drawing the child's attention to the importance of self-control can modify the child's economic behaviour. However, it is worth noting that, in both groups, irrespective of their condition, children tended to choose the saving option ("bank"). Taking into account the results of earlier research, we suspected that boys would present weaker self-control than girls; thus, they would have more problems with delaying gratification (choosing "bank"). Indeed, independent from the study condition, $74 \%$ of girls chose "bank" (saving option), while only $58.8 \%$ of boys made this choice. Further analysis showed that boys chose "bank" significantly less often than girls $\left(\chi^{2}(1)=\right.$ 4.006; $p=.045)$. Taking into account gender difference in children's choices, we conducted separate analyses of experimental manipulation effects for boys and girls. Those analyses revealed that the induced thinking about selfcontrol led to more frequent saving behaviours (choosing "bank") in boys, $\chi^{2}(1)=5.446 ; p=.020$, but not in girls; $\chi^{2}(1)=2.321 ; p=.128$ (see Fig. 2).

\section{Study 3}

The results of the second study showed that priming children to think about the importance of self-control could lead to more frequent saving behaviours. Self-control mainly refers to the goal-achieving effects but neglects the process of goal pursuit, e.g., the motivation of the activities. Therefore, our next study aimed to fill this gap by verifying the role of selfregulation motivations in realising saving goals. In this study, we verified two hypotheses about the influence of induced regulatory focus (promotion or prevention) on children's saving behaviours.

In both of our studies, saving behaviour was defined as refraining from consumption for one week. The choice of saving meant that the child, after one week, received more tokens (six instead of five) and was able to spend more in the "shop" set up for the purpose of the study. It is worth noting that this saving goal was purely promotional, because it concerned saving in order to have more goods, which satisfied the growth need. Thus, taking into account that satisfaction of growth needs is very important for promotionmotivated people, we suspected that children with induced promotion regulatory focus would be more prone to save tokens. However, given that prevention-oriented people are less prone to save for promotion goals (Cho et al. 2014), due to lack of regulatory fit, we suspected that children with induced prevention regulatory focus would be less prone to save tokens. In the third study, we verified the following hypotheses:

\section{Hypothesis 2a}

Induced promotion regulatory focus leads to preferring saving over immediate consumption.

\section{Hypothesis $2 b$}

Induced prevention regulatory focus leads to preferring immediate consumption over saving.

\section{Participants}

In the study, 144 Polish children ( 86 girls and 58 boys) aged 9 to 10 years $(M=9.70, S D=.46)$ took part in the third study. The research was carried out in three public primary schools in Warsaw, Poland. Parents of all the children provided written informed consent for their children's participation in the study, and all children provided oral assent to take part in the study.

\section{Procedure}

The procedure in Study 3 was similar to that used in Study 2. The study consisted of two parts run by different experimenters: (1) experimental manipulation with the manipulation 
Fig. 2 "Shop" vs. "Bank" choice in experimental and control groups, depending on child's gender

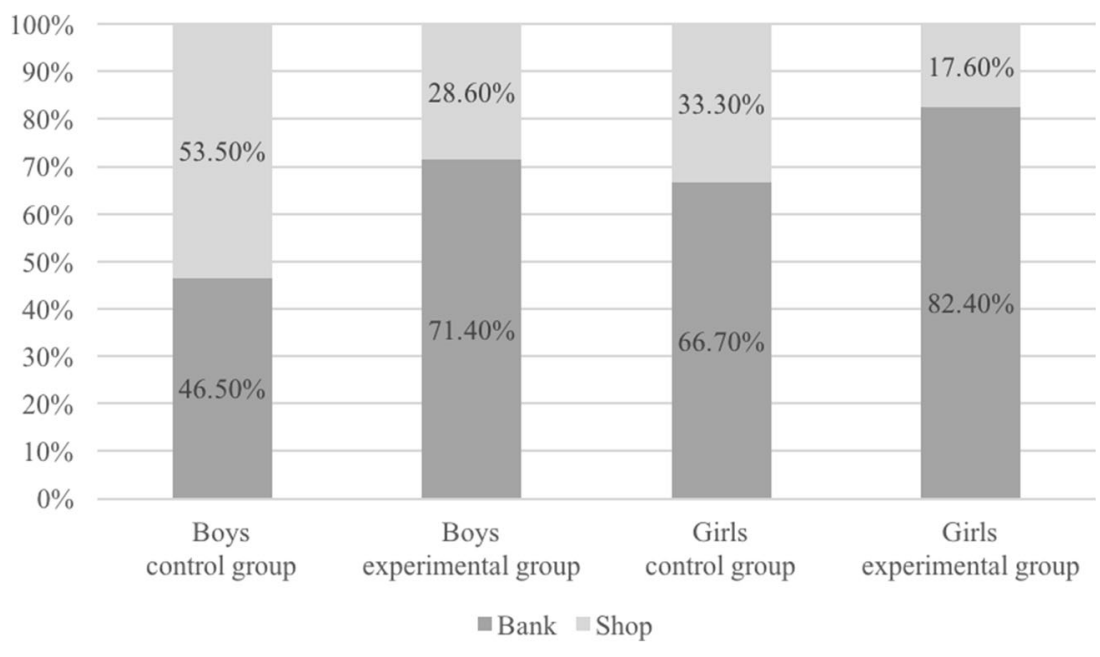

effectiveness check and (2) measure of financial behaviour (saving or immediate consumption choice - DV). The study was carried out individually, and participants were randomly assigned to one of three groups: (a) induced prevention regulatory focus (I experimental condition), (b) induced promotion regulatory focus (II experimental condition) or (c) cycling (control condition).

In order to induce specific regulatory focus (experimental manipulation), films especially created for the experiment were used. They were constructed based on a similar structure as the films in Study 1. Each film lasted about one minute and consisted of two parts. The first part explained what aspects of life the particular skill ("motivation" in both experimental conditions or "cycling" in the control condition) might be helpful. The second part of the film presented some examples from real life. In the first experimental condition, we induced in children the promotion focus by presenting them the film, clarifying, among other points, that motivation is a skill that helps one to concentrate on succeeding and to realise goals and a skill that helps one not hesitate to make risky decisions. The real-life examples in this condition were, among others: "when you study for a test to get a good grade", "when you are doing some sport in order to be more fit", or "when you speak in a discussion, even though you have a different opinion than everyone else". The film used for the second experimental condition in order to induce prevention focus explained that motivation is a skill that helps one to concentrate on avoiding failures and defeats and to make safe decisions. The real-life illustrations in this condition were, for example: "when you study for a test not to get a poor grade", "when you are doing some sport in order not to be weaker than your colleagues", or "when you do not speak in a discussion, because you have a different opinion than everyone else". In the control condition, children watched the same film that was used for the control condition in the first study (about the benefits of cycling).

As in the second study, in the second part of the experiment (after experimental manipulation), children answered two questions about the film (manipulation check) and got five tokens that they could spend in the "shop" set up for the purpose of the study or that they could deposit in the "bank" for one week to gain one more token. This part of the experiment was exactly the same as in the first study and measured the children's economic behaviour, i.e., the choice made by the child ("bank" or "shop").

\section{Results}

Our hypotheses assumed that children with induced promotion regulatory focus would choose "bank" (saving option) more often, while children with induced prevention regulatory focus would choose "bank" less often. The results of the experiment revealed that economic behaviour (saving vs. consumption) was different, depending on the experimental manipulation; $\chi^{2}(2)=8.257 ; p<.016$. A consideration of the adjusted standardised residuals revealed that children from the first experimental group with induced promotion focus chose "bank" (saving option) more often than expected, but children from the second experimental group with induced prevention focus chose "bank" less often than expected (Fig. 3). The results showed that the participants from the control group chose the "bank" option as often as was theoretically expected (Fig. 3). These data support both hypotheses of the third study and indicate that inducing specific regulatory focus (promotion or prevention) could modify the children's economic behaviour.

The next analysis compared financial choices by boys and girls. Taking into account all study groups together, as in Study 2, in the third study, girls chose "bank" over "shop" more often than boys did $(67.4 \%$ of girls compared to $46.6 \%$ of boys chose the "bank" option), which can be interpreted as higher self-control of girls than of boys $\left(\chi^{2}(1)=6.250 ; p=.012\right)$. The separate analyses of experimental manipulation effects for boys and girls have been conducted. They revealed that children's economic 
Fig. 3 "Shop" vs. "Bank" choice, depending on the experimental group

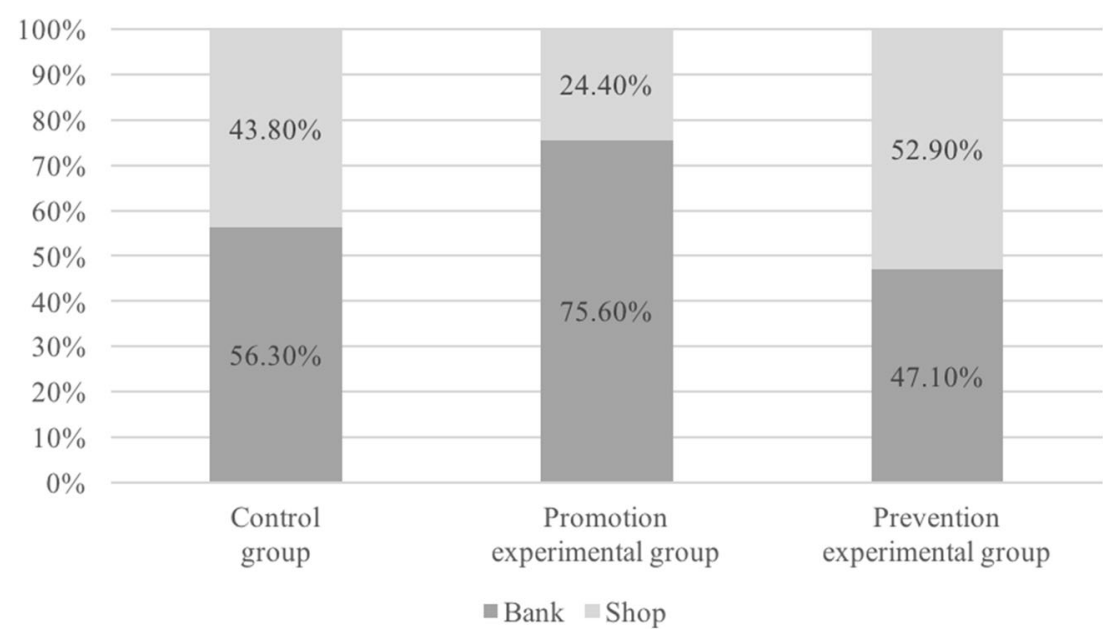

\section{Discussion}

The aim of our studies was to examine if the children's economic behaviour could be modified by drawing their attention to the importance of self-control or by inducing in the child specific regulatory focus (promotion vs. prevention). All our hypotheses were confirmed. The saving behaviour was chosen more often than current consumption by children in whom thinking about self-control was experimentally induced. The same effect was obtained for children in whom promotion regulatory focus was induced, but children with induced prevention regulatory focus preferred immediate consumption over saving.

The results of the present study confirmed that it is possible (at least in the short time) to influence economic behaviours of children by activation of thinking about the importance of self-control, and these support the results obtained by Lindroos (2015). theoretically expected.

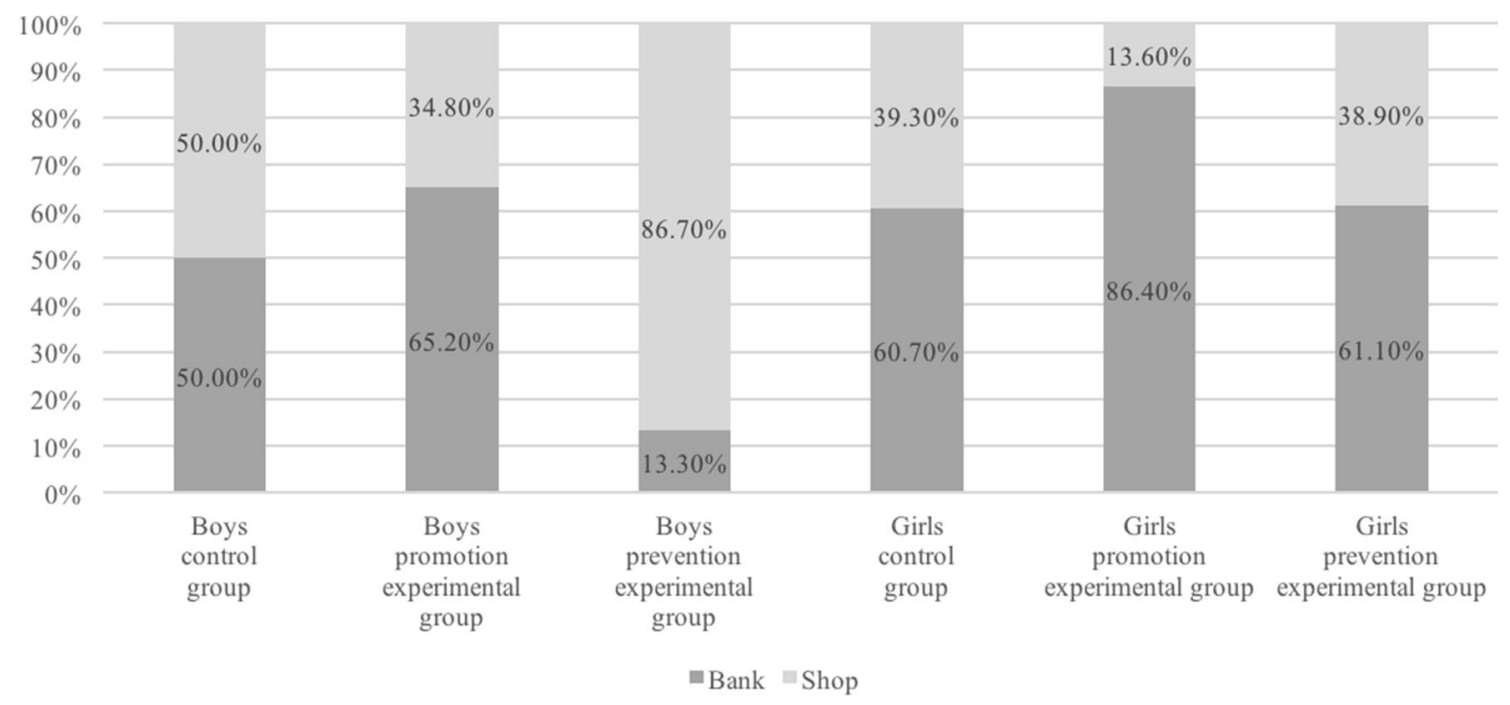

Fig. 4 "Shop" vs. "Bank" choice in experimental and control groups, depending on child's gender 
Although previous research, as well as our first (pretest) study, indicated that self-control as a trait is connected to saving behaviours of adults, adolescents, and children (Brändstatter and Güth 2000; Otto 2009; Trzcińska and Goszczyńska 2015), the studies were solely correlational. Therefore, based on these results, it is impossible to state if, by shaping self-control in children, it is possible to influence children's economic behaviour. Taking into account that creating proper children's economic decisions may be significant, since they can become the basis of behaviours and habits in adult life, the results of our studies are an important clue, indicating that, with non-specific (not related to financial behaviour) activation of the self-control concept, it is possible to influence children's saving behaviours.

It is worth noting that activation of thinking about self-control may indicate specific self-regulation motivations (promotion vs. prevention). For example, if we activate self-control, we can say that it is important, because it can help us save money, but we can also activate specific motivations by saying, for example, that it is worth attaining our goals (promotion focus) or feeling secure (prevention focus). The results of our third study indicated that inducing specific regulatory focus in children may influence their economic choices. Children with induced promotion focus decided to save more often, while children with induced prevention focus chose immediate consumption more often. Previous research (Sekścińska et al. 2016) revealed that both promotion and prevention orientations may support saving, but Cho et al. (2014) showed that the final effect of regulatory focus on saving behaviour may depend largely on the regulatory fit between motivation of the person and the type of saving goal (promotion vs. prevention). Promotion goals relate to nurturance and growth needs (e.g., saving for buying/investing in one's own business, saving for travels, saving for buying a house, etc.) and prevention goals to safety needs (e.g., saving for retirement/old age, saving in case of illness, saving for "rainy days", saving for "security" and independence, etc.) (Cho et al. 2014). In our studies, the saving goal (saving five tokens in order to gain one token of interest) was purely promotional, because it concerned saving in order to have more goods, which satisfies the growth need. The results of our studies in which children in promotion activation condition chose saving over immediate consumption more often, while children in prevention activation condition chose immediate consumption more often, indicated that regulatory fit has an important role in saving behaviours among children. Such a result supports findings of Cho et al. (2014), who showed that promotion-oriented people were more prone to save for promotion goals, while for prevention-oriented people, the effect was opposite.

Taking into account gender differences in self-control and regulatory foci, as reported in the literature (Higgins and Tewksbury 2006; McKay-Nesbitt et al. 2013), both our studies analysed experimental manipulation separately for boys and girls. First, our research confirmed earlier observed findings that girls have stronger self-control that can be manifested into financial behaviour more concerned with saving (delayed gratification) than with immediate consumption. In both studies, girls more often deposited their tokens in the "bank" (with one token interest) instead of immediately spending tokens in the "shop". After the activation of thinking about self-control, boys' preferences between saving and current consumption changed. They chose saving more often than expected. That result is in line with our expectation. However, no results of self-control activation were observed in the girls' group. It can be explained by the base level of the self-control, which is generally higher in females than in males (Higgins and Tewksbury 2006; Shoenberger and Rocheleau 2017). Therefore, without any self-control activation, they may prefer saving (which requires self-control) over immediate consumption. This relationship was also observed in the present studies. Girls chose "bank" more often than boys, which may be explained as a higher level of self-control. Because the inclination for self-control, and consequently the choice of the "bank" instead of consumption, was already high among girls, the experimental activation of self-control did not change their financial choices significantly, which were already determined by an internally high propensity to save.

The present study showed the role of promotion regulatory focus activation on boys' and girls' saving vs. current consumption preferences. Both boys and girls chose the "bank" more often than expected after the promotion focus activation. Based on the Cho et al. (2014) studies, it can be expected that the fit between type of the goal (promotional) and activated regulatory focus (promotion) is an important explanation of the results obtained in the present study. The activation of prevention regulatory focus resulted in more "current consumption" choices in the boys' group, while no effect was observed in the girls' group. The result for boys confirmed our expectation, but the result for girls does not confirmed our hypothesis. Since girls are more prevention oriented than boys, and the prevention-oriented people are less prone to save for promotion goals and more prone to save for prevention goals (Cho et al. 2014), it seems worth conducting the next study with the prevention goal to verify the relationship between prevention motivation activation and girls' saving vs. current consumption preferences.

\section{Limitations and Further Directions}

The present studies have certain limitations. The first is that we used in our studies only one type of saving goal: i.e., promotion, not prevention goal. Therefore, it would be worthwhile to carry out further studies in which children could choose a prevention saving goal, e.g., precautionary saving (for unexpected needs). Then, taking into account findings of Cho et al. (2014), results of regulatory foci activation in children may be different. The second limitation is that, in our experiment, children could choose between saving ("bank") and consumption ("shop") but were obliged to use all tokens for one of those options. It seems important to conduct new studies with the scenario in which children 
are asked to divide their tokens between current consumption and saving. In such a scenario, stronger preferences for saving would be observed as a higher number of tokens assigned to saving over consumption. It is possible that the role of self-control and prevention regulatory focus activation in the girls' group might be significant, if participants were asked to divide their tokens between saving and current consumption. One more possible limitation of our studies is the fact that we did not control the base level of children's self-control and regulatory foci; therefore, it would be worth measuring those variables in further studies.

Previous studies showed how the ability to delay gratification (Steinberg et al. 2009) and willingness to save (Otto 2009) change with age. However, there is a lack of research that examines the developmental trajectory of the effectiveness of psychological interventions that might increase saving abilities in children. Future studies might be useful to verify if interventions proposed in our studies (inducing self-control or promotion regulatory focus) can effectively influence saving behaviours among children at different ages. Simultaneously, longitudinal studies would be worthwhile to check how long the effects obtained in our studies last and if frequent repetitions of inducing self-control or specific regulatory foci bring the same effects.

\section{Conclusions}

The findings of our studies further our knowledge in the field of the effectiveness of psychological interventions that may improve self-control abilities and influence saving behaviours in children. Moreover, those studies answer applied questions about how to increase in children the desirable economic behaviour (saving). Nevertheless, future studies may provide important insights as to why inducing self-control and specific regulatory focus in children has different effects on economic decisions, depending on a child's gender.

Presented studies also have important implications for financial education strategies. They show that financial education does not just require providing children with knowledge about the utility of particular financial behaviours. It can be also accomplished by cognitive activation of concepts of individual skills (such as self-control or regulatory focus). The results of our research may also be a guide for parents giving children pocket money and wanting to develop in children the habit of saving. Earlier research showed that giving children allowances improves knowledge of money and its value (Kupisiewicz 2004) but does not entail a greater willingness to save (Otto 2009), unless parents provide guidance with regard to saving and spending money. Giving children allowances and reminding them of the importance of self-control as well as activating promotion regulatory focus might be useful strategies to strengthen children's saving abilities.

Funding This work was supported by the Polish National Science Centre (NCN), grant no. DEC-2013/11/B/HS6/01163.

\section{Compliance with Ethical Standards}

Ethical Approval All procedures performed in studies involving human participants were in accordance with the ethical standards of the institutional research committee and with the 1964 Helsinki declaration and its later amendments or comparable ethical standards. Informed consent was obtained from all individual participants included in the study. Parents of all the children participating in the research provided written informed consent for their children's participation in the study. This article does not contain any studies with animals performed by any of the authors.

Conflict of Interest The authors declare that there are no potential conflicts of interest with respect to the research, authorship, and/or publication of this article.

Open Access This article is distributed under the terms of the Creative Commons Attribution 4.0 International License (http:// creativecommons.org/licenses/by/4.0/), which permits unrestricted use, distribution, and reproduction in any medium, provided you give appropriate credit to the original author(s) and the source, provide a link to the Creative Commons license, and indicate if changes were made.

\section{References}

Ashby, J. S., Schoon, I., \& Webley, P. (2011). Save now, save later? Linkages between saving behavior in adolescence and adulthood. European Psychologist, 16(3), 227-237.

Ayduk, O., Mendoza-Denton, R., Mischel, W., Downey, G., Peake, P., \& Rodriguez, M. L. (2000). Regulating the interpersonal self: Strategic self-regulation for coping with rejection sensitivity. Journal of Personality and Social Psychology, 79, 776-792.

Baumeister, R. F., Bratslavsky, E., Muraven, M., \& Tice, D. M. (1998). Ego depletion: Is the active self a limited resource? Journal of Personality and Social Psychology, 74, 1252-1265.

Berti, E. A., \& Bombi, A. S. (1988). The child's construction of economics. Cambridge: Cambridge University Press.

Brändstatter, H., \& Güth, W. (2000). A psychological approach to individual differences in intertemporal consumption patterns. Journal of Economic Psychology, 21(2000), 465-479.

Bryant, P., \& Dunford, R. (2008). The influence of regulatory focus on risky decision- making. Applied Psychology, 57(2), 335-359.

Cho, S. H., Loibl, C., Geistfeld, L. V., \& Haugtvedt, C. (2014). Motivation for emergency and retirement saving: An examination of regulatory focus theory. International Journal of Consumer Studies, 38(6), 701-711.

de Ridder, D. T., Lensvelt-Mulders, G., Finkenauer, C., Stok, F. M., \& Baumeister, R. F. (2012). Taking stock of self-control: A metaanalysis of how trait self-control relates to a wide range of behaviors. Personality and Social Psychology Review, 16, 76-99. https://doi. org/10.1177/1088868311418749.

Förster, J., \& Werth, L. (2007). How regulatory focus influences consumer behavior. European Journal of Social Psychology, 37, 33-51.

Förster, J., Higgins, E. T., \& Bianco, A. T. (2003). Speed/accuracy decisions in task performance: Built-in trade-off or separate strategic concerns? Organizational Behavior and Human Decision Processes, 90, 148-164. https://doi.org/10.1016/S0749-5978(02)00509-5.

Friedman, R. S., \& Förster, J. (2001). The effects of promotion and prevention cues on creativity. Journal of Personality and Social Psychology, 81, 1001-1013.

Goszczyńska, M. (2010). Transformacja ekonomiczna $w$ umysłach $i$ zachowaniach Polaków. Warszawa: Wydawnictwo Naukowe Scholar.

Gottfredson, M. R., \& Hirschi, T. (1990). A general theory of crime. Stanford: Stanford University Press. 
Green, L., Fry, A. F., \& Myerson, J. (1994). Discounting of delayed rewards: A life-span comparison. Psychological Science, 5, 33-36.

Hagger, M. S., Wood, C., Stiff, C., \& Chatzisarantis, N. L. D. (2010). Ego depletion and the strength model of self-control: A meta-analysis. Psychological Bulletin, 136, 495-525. https://doi.org/10.1037/ a0019486.

Hay, C., \& Forrest, W. (2006). The development of self-control: Examining self-control theory's stability thesis. Criminology, 44, 739-773.

Higgins, E. T. (1987). Self-discrepancy: A theory relating self and affect. Psychological Review, 94, 319-340.

Higgins, E. T. (1997). Beyond pleasure and pain. American Psychologist, 52(12), 1280-1300.

Higgins, E. T. (1998). Promotion and prevention: Regulatory focus as a motivational principle. In M. P. Zanna (Ed.), Advances in experimental social psychology (Vol. 30, pp. 1-46). New York: Academic Press.

Higgins, E. T. (2000). Making a good decision: Values from fit. The American Psychologist, 55(11), 1217-1230.

Higgins, G., \& Tewksbury, R. (2006). Sex and self-control theory: The measures and causal model may be different. Youth and Society, 37(4), 479-503.

Higgins, E. T., Friedman, R. S., Harlow, R. E., Idson, L. C., Ayduk, O. N., \& Taylor, A. (2001). Achievement orientations from subjective experiences of success: Promotion pride versus prevention pride. European Journal of Social Psychology, 31, 3 23. https://doi.org/10.1002/ejsp.27.

Higgins, G. E., Jennings, W. G., Tewksbury, R., \& Gibson, C. L. (2009). Exploring the link between low self-control and violent victimization trajectories in adolescents. Criminal Justice and Behavior, 36, $1070-1084$

Keller, J. (2008). On the development of regulatory focus: The role of parenting styles. European Journal of Social Psychology, 38, 354-364.

Kendler, H. H., Kendler, T. S., \& Marken, R. S. (1969). Developmental analysis of reversal and half-reversal shifts. Developmental Psychology, 1, 318-326.

Kupisiewicz, M. (2004). Edukacja ekonomiczna dzieci. Z badań nad rozumieniem wartości pieniadza i obliczeniami pieniężnymi. Warszawa: Akademia Pedagogiki Specjalnej im. Marii Grzegorzewskiej.

Lee, A. Y., \& Higgins, E. T. (2009). The persuasive power of regulatory fit. In M. Wanke (Ed.), Social psychology of consumer behavior (pp. 319-333). New York: Psychology Press, Taylor \& Francis Group.

Liberman, N., Molden, C. D., Idson, C. L., \& Higgins, E. T. (2001). Promotion and prevention focus on alternative hypotheses: Implications for attributional functions. Journal of Personality and Social Psychology, 80(1), 5-18.

Lindroos, H. (2015). The art of measurement - Exogenous activation of self-control with simple verbal sentences in intertemporal choice. Student essay, University of Gothenburg.

Lockwood, P., Jordan, C. H., \& Kunda, Z. (2002). Motivation by positive or negative role models: Regulatory focus determines who will best inspire us. Journal of Personality and Social Psychology, 83, 854-864.

Lyons, A. (2003). Credit practices and financial education needs of Midwest college students (report). Urbana-Champaign: University of Illinois at Urbana-Champaign.

McKay-Nesbitt, J., Bhatnagar, N., \& Smith, M. C. (2013). Regulatory fit effects of gender and marketing message content. Journal of Business Research, 66(11), 2245-2251.

Miles, E., Sheeran, P., Baird, H., Macdonald, I., Webb, T. L., \& Harris, P. R. (2016). Does self-control improve with practice? Evidence from a six-week training program. Journal of Experimental Psychology, 145(8), 1075-1091.

Mischel, W. (2014). The marshmallow test: Mastering self-control. New York: Hachette Book Group.

Mischel, W., Shoda, Y., \& Peake, P. K. (1988). The nature of adolescent competencies predicted by preschool delay of gratification. Journal of Personality and Social Psychology, 54, 687-699.
Mischel, W., Shoda, Y., \& Rodriguez, M. L. (1992). Delay of gratification in children. In W. G. Loewenstein \& J. Elster (Eds.), Choice over time (pp. 147-164). New York: Russell Sage Foundation.

Muraven, M., \& Baumeister, R. F. (2000). Self-regulation and depletion of limited resources: Does self-control resemble a muscle? Psychological Bulletin, 126, 247-259. https://doi.org/10.1037/0033-2909.126.2.247.

Muraven, M., Baumeister, R. F., \& Tice, D. M. (1999). Longitudinal improvement of self-regulation through practice: Building selfcontrol through repeated exercise. Journal of Social Psychology, $139,446-457$.

Otto, A. M. C. (2009). The economic psychology of adolescent saving. Unpublished doctoral dissertation, University of Exeter, Exeter.

Pechman, C., Levine, L., Loughlin, S., \& Leslie, F. (2005). Impulsive and self-conscious: Adolescents' vulnerability to advertising and promotion. Journal of Public Policy and Marketing, 24, 202-221.

Rorhbeck, C., Azar, S., \& Wagner, P. E. (1991). Child self-control rating scale: Validation of a child self-report measure. Journal of Clinical Child and Adolescent Psychology, 20(2), 179-183.

Rudzińska-Wojciechowska, J., Trzcińska, A., \& Maison, D. (2011) Co dzieci wiedzą o bankach? Rozwój rozumienia zasad funkcjonowania banków u dzieci w wieku 4-12 lat. Ruch Pedagogiczny nr, 5-6, 61-75.

Sekścińska, K., Maison, D., \& Trzcińska, A. (2016). How people's motivational system and situational motivation influence their risky financial choices. Frontiers in Psychology, 7, 1360. https://doi.org/ 10.3389/fpsyg.2016.01360.

Shah, J., Higgins, E. T., \& Friedman, R. S. (1998). Performance incentives and means: How regulatory focus influences goal attainment. Journal of Personality and Social Psychology, 74(2), 285-293.

Shoda, Y., Mischel, W., \& Peake, P. K. (1990). Predicting adolescent cognitive and self-regulatory competencies from preschool delay of gratification: Identifying diagnostic conditions. Developmental Psychology, 26, 978-986.

Shoenberger, N., \& Rocheleau, G. C. (2017). Effective parenting and selfcontrol: Difference by gender. Women and Criminal Justice, In Press, 1-16. https://doi.org/10.1080/08974454.2016.1261071

Steinberg, L., Graham, S., O'Brien, L., Woolard, J., Cauffman, E., \& Banich, M. (2009). Age differences in future orientation and delay discounting. Child Development, 80, 28-44.

Størksen, I., Ellingsen, I. T., Wanless, S. B., \& McClelland, M. M. (2015). The influence of parental socioeconomic background and gender on self-regulation among 5-year-old children in Norway. Early Education and Development, 26(5-6), 663-684.

Thaler, R. H., \& Shefrin, H. M. (1981). An economic theory of selfcontrol. Journal of Political Economy, 89(2), 392-406.

Trzcińska, A., \& Goszczyńska, M. (2015). The role of mothers in economic socialization of saving behaviour in Polish adolescents / El rol de las madres en la socialización ecónomica del comportamiento de ahorro de los adolescentes polacos, Revista de Psicología Social: International Journal of Social Psychology. https://doi.org/10.1080/ 21711976.2015.1016757

Vazsonyi, A. T., \& Jiskrova, G. K. (2017). On the development of selfcontrol and deviance from preschool to middle adolescence. Journal of Criminal Justice, 56, 60-69. https://doi.org/10.1016/j.jcrimjus. 2017.08.005.

Webley, P., \& Nyhus, E. K. (2006). Parents' influence on children's future orientation and saving. Journal of Economic Psychology, 27, 140-164.

Webley, P., \& Nyhus, E. K. (2013). Economic socialization, saving and assets in European young adults. Economics of Education Review, 33, 19-30.

Zawadzka, A. M., Rybarczyk-Adamska, J., \& Dedelis, A. (2012). Jak promocyjne i prewencyjne ukierunkowanie samoregulacyjne wiąże się z ważnością cech i intencją zakupu produktu? Roczniki Psychologiczne, XIV(2), 31-53.

Zhou, R., \& Pham, M. T. (2004). Promotion and prevention across mental accounts: When financial products dictate consumers \& investment goals. Journal of Consumer Research, 31, 125-135. https://doi.org/ $10.1086 / 383429$. 